(С) Е.Н. Каспарова, Г.В. Скриган, В.И. Дунай

\title{
ИЗМЕНЧИВОСТЬ ПОКАЗАТЕЛЕЙ МАСКУЛИННОСТИ СТУДЕНЧЕСКОЙ МОЛОДЕЖИ БЕЛАРУСИ*
}

Цель исследования - оценить изменчивость морфофункииональных показателей маскулинности студенческой молодежи Беларуси во времени и в зависимости от уровня физической подготовки. Исследование проведено в 2016-2021 г2. в г. Минске (Республика Беларусь). Выборку составили 233 студента (102 юноши, 131 девушка) в возрасте от 18 до 21 года. Привлечень также материаль нашего исследования 180 студентов (125 юношей и 65 девушек) Белорусского государственного университета физической культуры. Материалом для сравнения послужили архивные данные отдела антропологии НАН Беларуси 2000-2007 гг.: всего 243 студента г. Минска (98 юношей, 145 девушек). Проведено антропометрическое измерение длины тела, массы тела, иирины плеч и таза, обхватов талии, бедер, плеча напряженного и расслабленного, длины второго и четвертого пальцев обеих рук, кистевой динамометрии правой и левой руки. Рассчитаны морфологические индексы. Выявлено, что у современных юношей обхват талии больше, чем у юношей начала XXI века. У девушек масса тела и обхват талии показали большую стабильность во времени. Ширина таза у представителей обоих полов от начала ХХІ века к современности уменьшилась. У современных юношей дисгармоничность телосложения за счет избыточности массы тела по отношению кего длине встречается чаще, чем в начале века. Показатели кистевой динамометрии у современной белорусской студенческой молодежи стали меньше по сравнению с началом 2000-х. Юноши и девушки, занимаюшиеся физической культурой, характеризуются более низкими значениями пальцевого индекса, чем те, кто имеет более низкий уровень физической подготовки. Таким образом, выявлень особенности изменчивости во времени у студенческой молодежи Беларуси таких показателей как обхват талии, иирина таза и динамометрия (силовые возможности), которые отразились на динамике морфологических индексов маскулинности.

Каспарова Елена Николаевна - старший преподаватель кафедры педагогики и проблем развития образования, Белорусский государственный университет (Республика Беларусь, Минск, 220030, пр-т Независимости, д. 4). Эл. почта: elena_arts@mail.ru

Скриган Галина Владимировна - к.б.н., доцент, заведующий кафедрой коррекционно-развивающих технологий, Учреждение образования «Белорусский государственный педагогический университет имени Максима Танка» (Республика Беларусь, Минск, 220030, ул. Советская, д. 18) Эл. почта: galanca@mail.ru

Дунай Валерий Иванович - к.б.н., доцент, ректор, Учреждение образования «Полесский государственный университет» (Республика Беларусь, г. Пинск, 225710, ул. Днепровской флотилии, д. 23) Эл. почта: dunay_wal@bk.ru

* Исследование проведено при финансовой поддержке следующих организаций и грантов: БРФФИ, Договор Г21MC-022 от 01.07.2021 г. «Социальные и биологические факторы адаптации студенческой молодежи Беларуси и Сербии к меняющимся условиям современной среды» 
Ключевые слова: антропометрические показатели, индексы маскулинности/фемининности, студенческая молодежь Беларуси

Ссылка при цитировании: Каспарова Е.Н., Скриган Г.В., Дунай В.И. Изменчивость показателей маскулинности студенческой молодежи Беларуси // Вестник антропологии, 2021. № 3. С. 134-151.

\section{Введение}

Время обучения в высшем учебном заведении приходится, преимущественно, на юношеский период онтогенеза. На этом этапе индивидуального развития в основном завершаются ростовые процессы, к его окончанию организм достигает дефинитивных размеров и выходит на относительно стабильный уровень функционирования, характерный для первого взрослого периода. Изменение условий среды может отражаться не только на темпах роста, но и на сроках его окончания. На протяжении $\mathrm{XX}$ столетия секулярные изменения в характере роста и развития проявились в ускорении их темпов у детей и подростков, астенизации телосложения со снижением силовых показателей, более раннем достижении дефинитивной длины тела, увеличении размеров тела у взрослых, удлинении репродуктивного периода и других сдвигах (Бахолдина, Негашева 2014).

Гормональные перестройки, запускающиеся к окончанию периода второго детства, определяют нарастание к юношескому периоду выраженности межполовых различий по размерам и пропорциям тела, компонентам состава тела, силовым показателям. В пубертате под влиянием мужских половых гормонов происходит активное нарастание мышечной массы тела, повышаются силовые возможности, что больше проявляется у представителей мужского пола. Женские половые гормоны стимулируют нарастание жирового компонента состава тела. Морфологическую мужественность связывают с высоким весоростовым индексом, высоким показателем относительной ширины плеч, низким пальцевым индексом, большей физической силой. Морфологическая женственность проявляется низкими значениями весоростового индекса, отношения талии к бедрам при высоком пальцевом индексе. Низкие значения отношения обхвата талии к обхвату бедер (waist-to-hip ratio (WHR)) могут быть связаны с нормальным или повышенным содержанием в организме эстрогенов (Дерябин 2008). Повышение отношения концентрации тестостерона к эстрогенам у женщин проявляется в увеличении абдоминальной подкожной и забрюшинной жировой клетчатки и, следовательно, повышенным значениям WHR. Соотношение обхватов талии и бедер имеет отрицательную корреляцию с уровнем тестостерона и у мужчин (Yong Shao et al. 2013). Однако все же, сила связи индекса отношения обхвата талии к обхвату бедер с уровнем тестостерона недостаточно сильная, что не позволяет рассматривать WHR как надежный биомаркер уровня андрогенов (Van Anders 2005).

В качестве морфологического признака, отражающего половые различия, предложен также пальцевой индекс 2D:4D (соотношение длины указательного и безымянного пальцев руки человека) (Manning et al. 2002). Превышение среднего значения второго пальца (указательного) над четвертым (безымянным), считают женским вариантом, превышение безымянного пальца над указательным - мужским (Manning et al. 2002). Связан ли пальцевой индекс с уровнем пренатальных половых стероидов 
остаётся предметом обсуждения. Утверждается, что соотношение цифр отрицательно коррелирует с пренатальным тестостероном, но положительно с воздействием эстрогена у новорожденных (Manning et al. 1998). Вместе с тем, по данным Э. Барит с соавторами, изучивших диады мать-дитя показали, что соотношение 2D:4D ребенка не было связано с концентрацией половых стероидов у матери на ранних сроках беременности (Barrett et al. 2020).

На онтогенетическую изменчивость маскулинных свойств организма влияет уровень двигательной активности человека. Многочисленными работами показано влияние занятий различными видами спорта на морфофункциональный статус. Сопоставление морфологических показателей, связанных с маскулинностью, в молодежных выборках с разным уровнем физической подготовки позволяет оценить их изменчивость в зависимости от данного фактора.

Цель исследования - оценить изменчивость морфофункциональных показателей маскулинности студенческой молодежи Беларуси обоего пола во времени и в зависимости от уровня физической подготовки.

\section{Материалы и методы}

Исследование проведено в течение 2016-2021 гг. на базе Белорусского государственного университета (БГУ), Белорусского государственного педагогического университета им. М. Танка (БГПУ). В исследовании приняли участие 233 студента

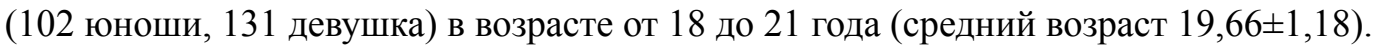
В 2016 - 2019 гг. нами обследовано 180 студентов (125 юношей и 65 девушек) Белорусского государственного университета физической культуры (БГУФК), занимающихся единоборствами и плаванием, в возрасте от 17 до 21 года (средний возраст

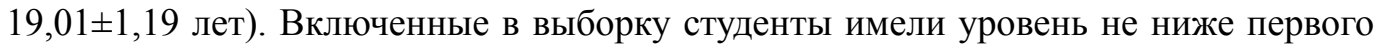
взрослого разряда при стаже спортивной деятельности не менее 5 лет. Большинство исследованных юношей и девушек по национальности белорусы - 78,9 \%.

Сравнительный анализ проведен с привлечением архивных материалов отдела антропологии Института истории Национальной академии наук Беларуси за 20002007 годы. Выборка была представлена 243 студентами г. Минска (98 юношей,

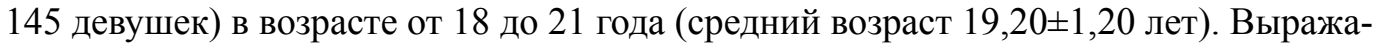
ем благодарность заведующему отделом антропологии Института истории и сотрудникам отдела за возможность использования материалов.

Антропометрическое обследование включало в себя определение длины тела, массы тела, ширины плеч, ширины таза, обхвата талии, обхвата бедер, обхвата плеча расслабленного, обхвата плеча напряженного, длины второго и четвертого пальцев обеих рук, кистевой динамометрии правой и левой рук (среднее значение). Все антропологические измерения проводились с использованием специальных антропологических инструментов стандартными методами (Мартиросов, Руднев, Николаев 2009).

На основании полученных антропометрических данных рассчитан ряд индексов.

1. Индекс Таннера определялся как разница между утроенной величиной ширины плеч и шириной таза (Хрисанфова, Перевозчиков 2005). Позволяет отнести индивида к одному из трех типов телосложения: андроморфия, мезоморфия, гинекоморфия.

2. Морфофункциональный индекс - индивидуальная характеристика морфофункциональных показателей, при его расчете учтены: длина тела, масса тела, 
ширина плеч, ширина таза, обхват талии, обхват бедер, обхват плеча расслабленного и напряженного, среднее значение динамометрии правой и левой рук (Мартиросов, Семенов, Мартиросова 2017). На основании полученного значения может быть выделен маскулинный, андрогинный или фемининный тип. Высокие значения индекса интерпретируются как выраженная маскулинность, низкие - как фемининность.

3. Пальцевой индекс определялся по величине отношения длины второго пальца к длине четвертого (2D:4D) (Manning et al. 1998). Значение индекса меньше 1 интерпретируется как проявление маскулинности, значение равное или больше 1 - как проявление фемининности. Измерение каждого пальца выполнялось от базальной складки до его кончика по два раза, использовали среднее значение.

4. Индекс отношения обхвата талии к обхвату бедер (WHR) отражает относительное распределение жира в верхней и нижней частях тела. Варианты его оценки (WHO 2008): мужчины - < 0,85 - отличный уровень, 0,85-0,90 - хороший, 0,90-0,95 - средний, 0,95-1,00 - высокий, > 1,00 - очень высокий; женщины - < 0,75 - отличный, 0,75-0,80 - хороший, 0,80-0,85 - средний, 0,85-0,90- высокий, $>0,90$ - очень высокий. Значения индекса выше 0,90 у мужчин и 0,85 у женщин - соотносятся по оценке со значениями ИМТ выше 30 (ожирение).

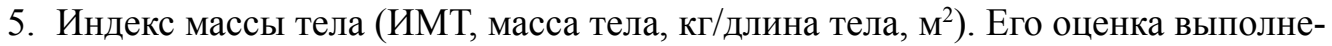
на в соответствии с рекомендациями ВО3: $<18,5$ - дефицит массы, 18,5-24,9нормальное соотношение, 25,0-29,9 - избыточный вес, $>30,0$ - ожирение.

Все материалы были собраны с соблюдением правил биоэтики; подписаны протоколы информированного согласия.

В процессе статистической обработки данных были рассчитаны центили и параметры описательной статистики. Для выявления тесноты парных связей признаков, обладающих непрерывной изменчивостью, использовался корреляционный анализ Спирмена. Оценка достоверности различий между выборками по уровню выраженности признаков выполнена с применением Т-критерия Стьюдента. С целью определения дифференцирующей значимости фактора пола для показателей маскулинности был использован однофакторный дисперсионный анализ.

\section{Результаты и обсуждение}

\section{Изменчивость во времени антропометрических показателей студенческой молодежи Беларуси}

В табл. 1 представлены результаты оценки значимости фактора пола для выраженности различий по индексу Таннера, индексу Мартиросова, отношению обхвата талии к обхвату бедер, ИМТ, пальцевому индексу, показателю кистевой динамометрии. Анализ межполовых различий в показателях маскулинности отражают общебиологические закономерности: маскулинность более выражена в мужской выборке, чем в женской.

Сопоставление морфологических показателей студентов, измеренных в начале XXI века, и современных позволило выявить у юношей высоко достоверное увеличение во времени обхвата талии ( $\mathrm{p}<0,001)$ и уменьшение ширины таза $(\mathrm{p}<0,01)$, с тенденцией к повышению массы тела ( $<0,05-0,09)$ (табл. 2).

Причем различия во времени по массе тела и обхвату талии в большей мере выражены у студентов младших курсов (18-19 лет), чем старших (20-22 года). Значение 
медианы по массе тела и ИМТ также выше у современных юношей. Увеличение к современности коэффициентов вариации по этим признакам (в том числе у девушек) может быть отражением неблагоприятного влияния внешней среды.

Таблица 1

Дифференцирующая значимость фактора пола для показателей маскулинности (2016-2021 гг.)

\begin{tabular}{l|c|c}
\hline Показатели маскулинности & F-критерий & $\mathbf{p}$ \\
\hline Индекс Таннера & 376,042 & 0,000 \\
Индекс Мартиросова & 1167,063 & 0,000 \\
Отношение: талия/бедра & 252,290 & 0,000 \\
ИМТ & 10,873 & 0,001 \\
\hline 2D:4D (правая рука) & 6,985 & 0,01 \\
\hline 2D:4D (левая рука) & 8,680 & 0,01 \\
\hline Динамометрия & 491,988 & 0,000 \\
\hline
\end{tabular}

Таблица 2

Статистические значения морфологических показателей студенческой молодежи Беларуси 2000-2007 и 2016-2021 гг. исследования

\begin{tabular}{|c|c|c|c|c|c|c|c|c|}
\hline \multirow{2}{*}{$\begin{array}{l}\text { Морфол о- } \\
\text { гические } \\
\text { показатели }\end{array}$} & \multirow{2}{*}{$\begin{array}{c}\text { Временной } \\
\text { период }\end{array}$} & \multirow{2}{*}{$\mathbf{M}$} & \multirow{2}{*}{ SD } & \multicolumn{3}{|c|}{ Процентили } & \multirow{2}{*}{$\mathrm{V}, \%$} & \multirow{2}{*}{$\mathbf{p}$} \\
\hline & & & & $25 \%$ & $50 \%$ & $75 \%$ & & \\
\hline \multicolumn{9}{|l|}{ Юноши } \\
\hline \multirow{2}{*}{$\begin{array}{l}\text { Длина тела, } \\
\text { см }\end{array}$} & $2000-2007$ & 177,23 & 6,34 & 172,40 & 177,00 & 181,00 & 3,58 & \multirow{2}{*}{-} \\
\hline & 2016-2021 & 178,44 & 6,26 & 174,30 & 177,40 & 182,30 & 3,85 & \\
\hline \multirow{2}{*}{$\begin{array}{l}\text { Масса тела, } \\
\text { кг }\end{array}$} & $2000-2007$ & 69,77 & 8,80 & 63,73 & 68,65 & 77,13 & 12,61 & \multirow{2}{*}{0,07} \\
\hline & 2016-2021 & 72,54 & 12,33 & 65,90 & 70,70 & 76,70 & 19,83 & \\
\hline \multirow{2}{*}{ ИМТ, кг/м² } & $2000-2007$ & 22,17 & 2,36 & 20,51 & 22,14 & 23,53 & 10,65 & \multirow{2}{*}{-} \\
\hline & 2016-2021 & 22,78 & 3,60 & 20,47 & 22,34 & 24,30 & 16,51 & \\
\hline \multirow{2}{*}{$\begin{array}{l}\text { Ширина } \\
\text { плеч, см }\end{array}$} & $2000-2007$ & 40,40 & 1,77 & 39,40 & 40,30 & 41,60 & 6,44 & \multirow{2}{*}{-} \\
\hline & 2016-2021 & 40,47 & 1,89 & 39,40 & 40,30 & 41,70 & 4,67 & \\
\hline \multirow{2}{*}{$\begin{array}{l}\text { Ширина } \\
\text { таза, см }\end{array}$} & $2000-2007$ & 28,96 & 2,67 & 27,20 & 28,60 & 30,00 & 9,22 & \multirow{2}{*}{0,01} \\
\hline & 2016-2021 & 27,99 & 1,76 & 26,80 & 28,10 & 29,10 & 6,66 & \\
\hline \multirow{2}{*}{$\begin{array}{l}\text { Индекс } \\
\text { Таннера }\end{array}$} & $2000-2007$ & 92,63 & 6,89 & 88,80 & 91,90 & 96,80 & 7,44 & \multirow{2}{*}{-} \\
\hline & 2016-2021 & 93,21 & 5,01 & 89,70 & 92,80 & 96,80 & 5,54 & \\
\hline \multirow{2}{*}{$\begin{array}{l}\text { Обхват } \\
\text { талии, см }\end{array}$} & $2000-2007$ & 75,89 & 6,16 & 71,00 & 75,50 & 80,00 & 8,12 & \multirow{2}{*}{0,001} \\
\hline & 2016-2021 & 79,47 & 8,81 & 74,20 & 78,00 & 82,00 & 12,12 & \\
\hline
\end{tabular}


Таблица 2 (продолжение)

\begin{tabular}{|c|c|c|c|c|c|c|c|c|}
\hline \multirow{2}{*}{$\begin{array}{l}\text { Морфоло- } \\
\text { гические } \\
\text { показатели }\end{array}$} & \multirow[b]{2}{*}{$\begin{array}{l}\text { Временной } \\
\text { период }\end{array}$} & \multirow[b]{2}{*}{$\mathbf{M}$} & \multirow[b]{2}{*}{ SD } & \multicolumn{3}{|c|}{ Процентили } & \multirow[b]{2}{*}{$\mathrm{V}, \%$} & \multirow[b]{2}{*}{$\mathbf{p}$} \\
\hline & & & & $25 \%$ & $50 \%$ & $75 \%$ & & \\
\hline \multicolumn{9}{|l|}{ Девушки } \\
\hline \multirow{2}{*}{$\begin{array}{l}\text { Длина тела, } \\
\text { см }\end{array}$} & $2000-2007$ & 165,89 & 6,05 & 161,50 & 166,00 & 170,00 & 3,65 & \multirow{2}{*}{-} \\
\hline & 2016-2021 & 166,31 & 6,29 & 161,90 & 166,10 & 170,50 & 3,78 & \\
\hline \multirow{2}{*}{$\begin{array}{l}\text { Масса тела, } \\
\text { кг }\end{array}$} & 2000-2007 & 57,49 & 9,20 & 51,50 & 55,00 & 62,50 & 16,00 & \multirow{2}{*}{-} \\
\hline & 2016-2021 & 58,84 & 10,37 & 52,50 & 56,60 & 64,00 & 17,62 & \\
\hline \multirow{2}{*}{ ИМТ, кг/м² } & $2000-2007$ & 20,89 & 3,12 & 18,95 & 20,12 & 21,98 & 14,94 & \multirow{2}{*}{-} \\
\hline & 2016-2021 & 21,25 & 3,45 & 19,00 & 20,58 & 22,83 & 16,24 & \\
\hline \multirow{2}{*}{$\begin{array}{l}\text { Ширина } \\
\text { плеч, см }\end{array}$} & 2000-2007 & 36,22 & 2,07 & 35,00 & 36,00 & 37,55 & 5,72 & \multirow{2}{*}{0,01} \\
\hline & 2016-2021 & 35,64 & 1,78 & 34,30 & 35,80 & 36,80 & 4,99 & \\
\hline \multirow{2}{*}{$\begin{array}{l}\text { Ширина } \\
\text { таза, см }\end{array}$} & $2000-2007$ & 27,85 & 3,24 & 25,45 & 27,00 & 30,00 & 11,63 & \multirow{2}{*}{0,001} \\
\hline & 2016-2021 & 26,76 & 2,10 & 25,20 & 26,30 & 28,00 & 7,85 & \\
\hline \multirow{2}{*}{$\begin{array}{l}\text { Индекс } \\
\text { Таннера }\end{array}$} & $2000-2007$ & 80,81 & 5,84 & 77,70 & 80,90 & 84,25 & 7,23 & \multirow{2}{*}{-} \\
\hline & 2016-2021 & 80,18 & 5,13 & 76,80 & 80,70 & 83,80 & 6,40 & \\
\hline \multirow{2}{*}{$\begin{array}{l}\text { Обхват } \\
\text { талии, см }\end{array}$} & $2000-2007$ & 68,67 & 6,88 & 64,00 & 67,50 & 71,00 & 10,02 & \multirow{2}{*}{-} \\
\hline & 2016-2021 & 68,74 & 6,90 & 64,40 & 67,90 & 70,70 & 10,04 & \\
\hline
\end{tabular}

Современные девушки характеризуются меньшими параметрами ширины плеч $(\mathrm{p}<0,01)$ и ширины таза ( $<0,001)$, чем девушки начала 2000-х годов. Различия в большей мере выражены в возрастной группе 20-22 года.

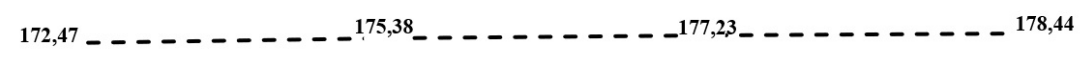

70,92 66,09 -69,72 $-73,31$

\begin{tabular}{c|c|c|c}
$1970-1980$ гг. & $1989-1997$ гг. & $2000-2007$ гг. & $2016-2021$ гг. \\
$18-36$ лет & 18 лет & $18-22$ лет & $18-22$ лет \\
И.И.Саливон (2019) & С.А.Ляликов и С.Д.Орехов & $\begin{array}{c}\text { О.В.Марфина, Т.Л.Гурбо } \\
\text { (неопубликованные) }\end{array}$ & Наши данные \\
& - - длина тела & - - Масса тела
\end{tabular}

Рис. 1. Изменения во времени длины тела и массы тела у юношей Беларуси.

Изменчивость во времени длины и массы тела молодежи Беларуси изучена с использованием данных из литературных источников за 1970-1980 гг. (Саливон 2019), 
1989-1997 гг. (Ляликов, Орехов 2000) и рассматриваемых в работе материалов. Отмечено поступательное увеличение длины тела от 1970-х годов к современности, как у юношей, так и девушек (рис. 1, 2). Масса тела у юношей от 1989 г. к современности возрастает, у девушек с 1970 г. показатель почти не изменяется, не показывая заметных различий во времени. Полученные нами результаты согласуются с отмеченной сербскими учеными тенденцией к увеличению массы тела у студентов юношей 2017-2018 гг. исследования по отношению к 1990-1991 гг. и большей стабильностью показателя у девушек (Чаплинская и др. 2019).

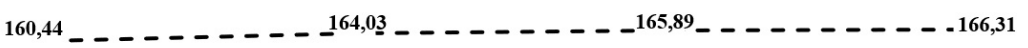

58,13 59,10 57,49 58,83

\begin{tabular}{|c|c|c|c|}
\hline $1970-1980$ гт. & $1989-1997$ гг. & $2000-2007$ гг. & $2016-2021$ гг. \\
$18-36$ лет & 18 лет & $18-22$ лет & $18-22$ лет \\
И.И.Саливон (2019) & С.А.Ляликов и С.Д.Орехов & $\begin{array}{c}\text { О.В.Марфина, Т.Л.Гурбо } \\
\text { (неоубликованные) }\end{array}$ & Наши данные \\
& $(2000)$ & - - Длина тела & - - Масса тела \\
\hline
\end{tabular}

Рис. 2. Изменения во времени длины тела и массы тела у девущек Беларуси.

Дополнительно юноши и девушки распределены на группы в зависимости от варианта оценки ИМТ. Частоты встречаемости различных оценок ИМТ для студенческой молодежи 2000-2007 гг. и 2016-2021 гг. представлены на рис. 3.

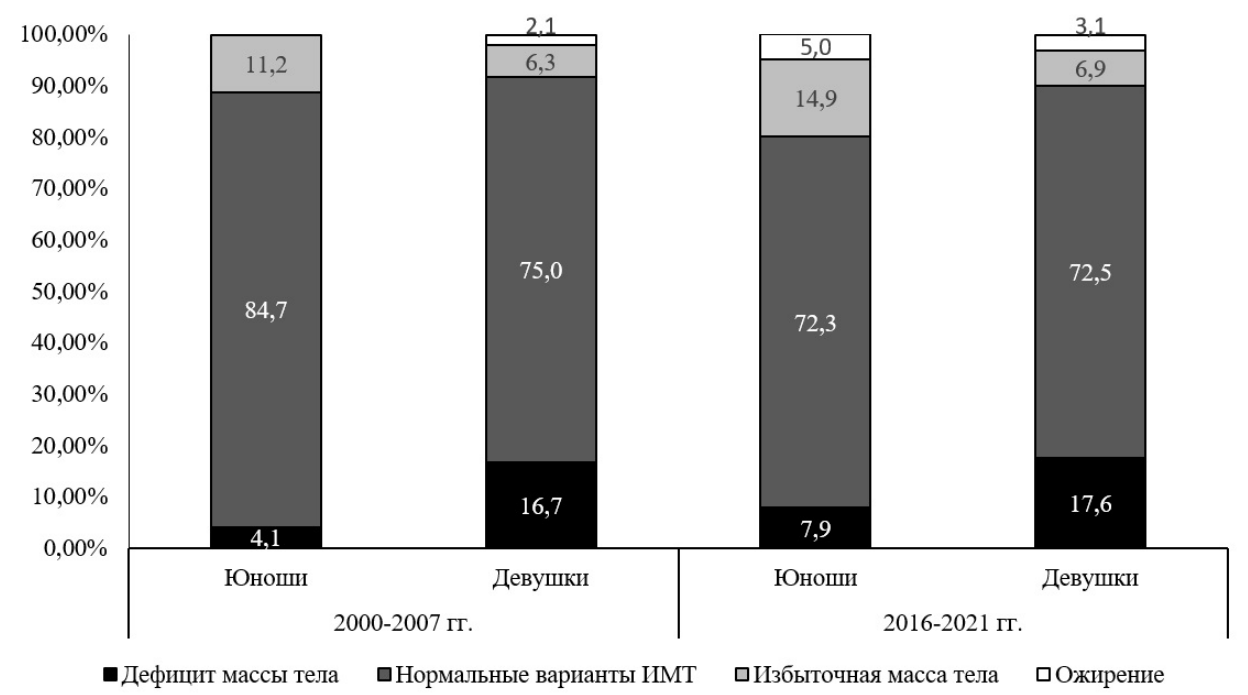

Рис. 3. Частоты встречаемости различных оценок ИМТ у юношей и девушек, обследованных в 2000-2007 г2. и 2016-2021 г2., \%. 
У современных юношей, в отличие от девушек, по отношению к студентам начала XXI века отмечено достоверное изменение характера распределения оценок ИМТ, которое выразилось в сокращении на $12,4 \%(\mathrm{p}<0,05)$ доли гармоничного варианта индекса за счет увеличения частоты встречаемости избыточной массы тела и ожирения (совокупно на 8,7\%). Нарастание ИМТ, так же как и обхвата талии, на наш взгляд, могут быть связаны с изменением характера питания и уровня двигательной активности молодежи. Предрасположенность к ожирению на 40-80\% определяется генетическими факторами (Silventoinen et al. 2016). Вместе с тем, на развитие избыточности массы тела оказывает влияние множество факторов окружающей среды (Dinescu et al. 2016; Schrempft et al. 2018) и образа жизни (Mustelin et al. 2009). Межполовые различия, выразившиеся в достоверном изменении распределения оценок ИМТ у юношей и устойчивости распределения у девушек, могут быть обусловлены их разными представлениями об идеалах красоты и соответственно отличающимися подходами к питанию и характеру физической активности. Известно стремление представительниц женского пола к тонкосложенным идеалам красоты. Ряд зарубежных исследований показывают связь ИМТ с привлекательностью у женщин: важными характеристиками их красоты являются определенные размеры тела (Huте, Montgomerie 2001; Kurzban, Weeden 2005; Tovée et al. 2002).

Массивность скелетных структур и выраженность отдельных компонентов сомы в определенной мере отражаются на величине ИМТ. Выполнен корреляционный анализ связи ИМТ с обхватом талии, который рекомендован как признак, который можно использовать как показатель избыточности жироотложения и обусловленного им риска для здоровья (WHO 2008). Значение коэффициента корреляции у современных юношей составило 0,856, у девушек - 0,890 при $p<0,001$, что выше соответствующего показателя у студентов начала XXI века (юноши $-\mathrm{R}=0,734$; девушки $-\mathrm{R}=0,745, \mathrm{p}<0,001)$. Отмеченное возрастание коэффициента корреляции у современной студенческой молодежи указывает на повышение прогностического значения обхвата талии при выявлении лиц с риском для здоровья.

Среднее значение отношения обхвата талии к обхвату бедер у современных юношей составило 0,81 , у девушек 0,72 (табл. 3). Показатели WHR у белорусской молодежи ниже, чем у юношей и девушек в возрасте $17-21$ года в Африке $(0,94$ и 0,77 соответственно) и Индии (0,84 и 0,79 соответственно) (Shabnam Suprava 2014). Среди белорусских юношей доля индивидов с WHR, превышающем нормальные значения $(>0,90)$, больше, чем среди девушек $(>0,85): 3,96 \%$ против $0,76 \%$.

Таблица 3

Статистические значения показателя соотношения обхвата талии к обхвату бедер у белорусских юношей и девушек

\begin{tabular}{c|c|c|c|c|c|c|c|c|c}
\hline \multirow{2}{*}{ Пол } & \multirow{2}{*}{ M } & \multirow{2}{*}{ SD } & \multicolumn{7}{|c}{ Процентили } \\
\cline { 4 - 10 } & & & $\mathbf{5 \%}$ & $\mathbf{1 5 \%}$ & $\mathbf{2 5 \%}$ & $\mathbf{5 0 \%}$ & $\mathbf{7 5 \%}$ & $\mathbf{8 5 \%}$ & $\mathbf{9 5 \%}$ \\
\hline Юноши & 0,81 & 0,05 & 0,75 & 0,77 & 0,77 & 0,81 & 0,84 & 0,85 & 0,88 \\
\hdashline Девушки & 0,72 & 0,04 & 0,66 & 0,68 & 0,69 & 0,72 & 0,75 & 0,76 & 0,80 \\
\hline
\end{tabular}

Сопоставление средних значений кистевой динамометрии современных студентов с юношами и девушками, обследованными в начале века, демонстрирует про- 
должающуюся тенденцию к снижению силовых возможностей молодежи (табл. 4).

Таблица 4

Статистические значения динамометрии правой и левой кистей рук у студенческой молодежи 2000-2007 и 2016-2021 гг. обследования

\begin{tabular}{|c|c|c|c|c|c|c|c|c|}
\hline \multirow{2}{*}{$\begin{array}{l}\text { Кистевая } \\
\text { динамометрия }\end{array}$} & \multirow{2}{*}{$\begin{array}{c}\text { Период } \\
\text { исследования }\end{array}$} & \multirow{2}{*}{$\mathbf{M}$} & \multirow{2}{*}{ SD } & \multicolumn{3}{|c|}{ Процентили } & \multirow{2}{*}{$\mathrm{V}, \%$} & \multirow{2}{*}{$\mathbf{p}$} \\
\hline & & & & $25 \%$ & $50 \%$ & $75 \%$ & & \\
\hline \multicolumn{9}{|l|}{ Юноши } \\
\hline \multirow{2}{*}{ Правая кисть } & 2000-2007 & 44,9 & 8,1 & 40,0 & 45,0 & 50,0 & 18,04 & \multirow{2}{*}{0,001} \\
\hline & 2016-2021 & 39,3 & 7,0 & 33,0 & 40,0 & 43,0 & 17,81 & \\
\hline \multirow{2}{*}{ Левая кисть } & 2000-2007 & 42,6 & 7,5 & 38,0 & 43,0 & 47,0 & 17,61 & \multirow{2}{*}{0,001} \\
\hline & $2016-2021$ & 36,6 & 6,4 & 32,0 & 36,0 & 40,0 & 17,49 & \\
\hline \multicolumn{9}{|l|}{ Девушки } \\
\hline \multirow{2}{*}{ Правая кисть } & 2000-2007 & 26,1 & 6,6 & 20,0 & 26,0 & 30,0 & 25,29 & \multirow{2}{*}{0,001} \\
\hline & 2016-2021 & 23,6 & 4,6 & 20,0 & 24,0 & 26,0 & 19,49 & \\
\hline \multirow{2}{*}{ Левая кисть } & 2000-2007 & 24,3 & 5,7 & 20,0 & 24,0 & 29,0 & 23,46 & \multirow{2}{*}{0,001} \\
\hline & $2016-2021$ & 21,8 & 4,1 & 19,0 & 22,0 & 24,0 & 18,81 & \\
\hline
\end{tabular}

Неблагоприятная динамика является следствием влияния множества факторов: образ жизни человека, недостаточная физическая подготовка и двигательная активность, ухудшение состояния среды обитания и др. Тенденция к снижению силовых возможностей у московских детей и подростков по сравнению со сверстниками, обследованными ранее, была обнаружена уже в конце 1990-х гг. (Ямпольская 1993). К началу 2000-х годов значения динамометрии белорусских подростков были даже меньше их ровесников 1960-х годов, несмотря на то с 60-х гг. до 1990 г. значения нарастали (Скриган 2009).

Уменьшение у девушек коэффициента вариации показателя кистевой динамометрии как правой, так и левой рук от начала века к современности свидетельствует о большей сбалансированности условий их жизни.

Морфологические показатели маскулинности и уровень физической подготовки студенческой молодежи Беларуси

В персональном информационном блоке студенты Белорусского государственного университета и Белорусского государственного педагогического университета им. М.Танка указывали, занимаются ли они спортом и имеют ли спортивный разряд. Юноши и девушки, занимающиеся спортом, из выборки исключались. Группа студентов БГУФК представлена квалифицированными спортсменами, которые имеют относительно высокий уровень физической подготовки, по сравнению со студентами двух других университетов.

Сопоставление антропометрических показателей юношей и девушек, с разным уровнем физической подготовки, показал, что у студентов БГУФК по большинству антропометрических характеристик наблюдаются неслучайные различия. Независимо от пола у студентов-спортсменов, по сравнению с теми, кто спортом не за- 
нимался высоко достоверно выше средние значения обхватов плеча в состоянии напряжения (юноши: $\mathrm{M}=34,11$ против $\mathrm{M}=31,42, \mathrm{p}<0,001$; девушки: $\mathrm{M=28,87}$ против $\mathrm{M}=26,75, \mathrm{p}<0,001$ ) и расслабления (юноши: $\mathrm{M}=31,52$ против $\mathrm{M}=29,51, \mathrm{p}<0,001$; девушки: $\mathrm{M}=28,87$ против $\mathrm{M}=26,75, \mathrm{p}<0,001$ ), кистевой динамометрии (юноши: $\mathrm{M}=44,02$ против $\mathrm{M}=38,21, \mathrm{p}<0,001$; девушки: $\mathrm{M}=27,74$ против $\mathrm{M}=22,68, \mathrm{p}<0,001)$.
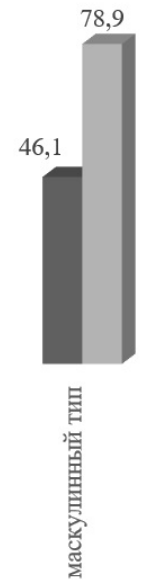

Индекс Мартиросова

舅

$$
\text { 恶 }
$$

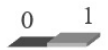

慁

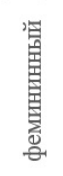

$$
\text { •Юноши (БГУ) }
$$
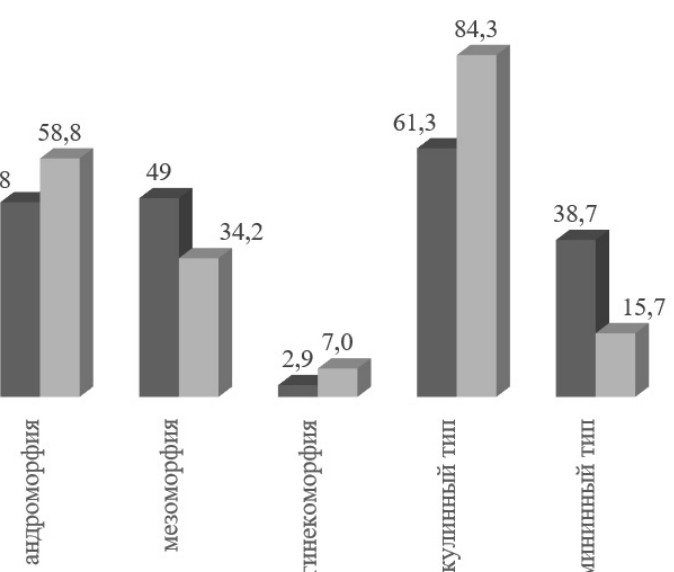

Индекс Таннера

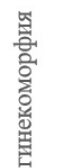

罢

2D:4D

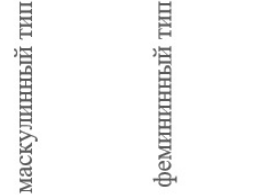

Рис. 4. Частоты встречаемости маскулинных/фемининных типов среди юномей с разным уровнем физической подготовки, \%.

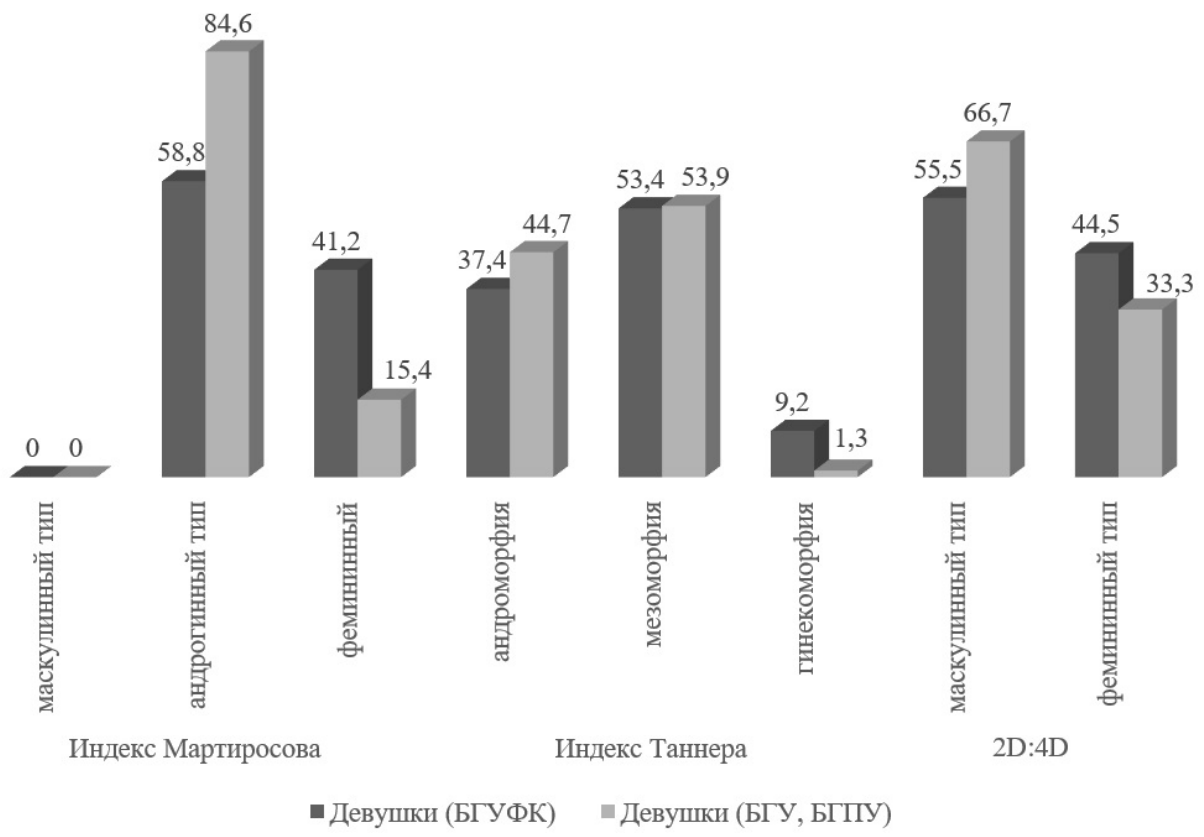

Рис. 5. Частоты встречаемости маскулинных/фемининных типов среди девушек с разным уровнем физической подготовки, \%. 
Обхват бедер достоверно больше у юношей-неспортсменов, чем у спортсменов ( $\mathrm{M}=98,34$ против $\mathrm{M}=96,03, \mathrm{p}<0,05)$. У девушек, занимающихся спортом, значения ширины плеч $(\mathrm{M}=36,48$ против $\mathrm{M}=35,64, \mathrm{p}<0,001)$ и таза $(\mathrm{M}=27,64$ против $\mathrm{M}=26,76$, $\mathrm{p}<0,01)$ больше, чем у студенток с обычным уровнем физической подготовки.

Студенты с высоким и обычным уровнем физической подготовки были распределены по типам выраженности маскулинности/фемининности на основании значений, рассчитанных с использованием индексов Мартисова, Таннера и Меннинга. Наибольшие различия между рассматриваемыми группами юношей и девушек по частотам представленности типов маскулинности/фемининности обнаружены по методике Мартиросова (рис. 4 и рис. 5).

Доля студентов мужского пола маскулинного типа (по Мартиросову) больше среди студентов БГУФК (78,9\%), характеризующихся высоким уровнем физической подготовки, чем среди студентов, не занимающихся активно физической культурой (46,1\%). Андрогинный тип в группе юношей, не занимающихся спортом, выделен в 52,9\% случаев. Среди девушек андрогинный тип чаще встретился у спортсменок $(84,6 \%)$, чем студенток не занимающихся активно физической культурой (58,8\%). В мужских выборках андроморфия, определенная по индексу Таннера, чаще встречается у «спортменов», чем у «неспортменов» (58,8\% против 48,0\%). У девушек данный тип в тех же группах представлен $37,4 \%$ и 44,7\% соответственно. Маскулинный тип пальцевого индекса, как в мужской, так и женской выборках чаще встречается у «спортсменов», чем у «неспортменов» (юноши: 38,7\% против 15,7\%; девушки: 44,5\% против 33,3\%).

Сопоставление показателей маскулинности у студентов обоего пола с высоким и обычным уровнем физической подготовки показало достоверные различия по индексу Мартиросова, отношению талия/бедра, пальцевому индексу правой и левой рук, среднему значению кистевой динамометрии: в «спортивных» выборках, по сравнению с «неспортивными», значения всех отмеченных показателей указывают на бо́льшую маскулинность (табл. 5). Девушки с высоким уровнем физической подготовки также имеют более высокое значения индекса Таннера.

Таблица 5

\section{Статистические значения показателей маскулинности у студентов, различающихся по уровню физической подготовки}

\begin{tabular}{|c|c|c|c|c|c|c|c|}
\hline \multirow{2}{*}{$\begin{array}{l}\text { Морфологические } \\
\text { показатели }\end{array}$} & \multirow{2}{*}{ Выборки } & \multirow{2}{*}{$\mathbf{M}$} & \multirow{2}{*}{ SD } & \multicolumn{3}{|c|}{ Процентили } & \multirow{2}{*}{$\mathbf{p}$} \\
\hline & & & & $25 \%$ & $50 \%$ & $75 \%$ & \\
\hline \multicolumn{8}{|l|}{ Юноши } \\
\hline \multirow{2}{*}{ Индекс Таннера } & БГУФК & 93,65 & 8,37 & 90,30 & 94,10 & 98,50 & \multirow{2}{*}{-} \\
\hline & БГУ & 93,21 & 5,01 & 89,70 & 92,80 & 96,80 & \\
\hline \multirow{2}{*}{ Индекс Мартиросова } & БГУФК & 83,68 & 12,84 & 76,54 & 83,23 & 92,42 & \multirow{2}{*}{0,001} \\
\hline & БГУ & 75,03 & 10,76 & 67,59 & 73,46 & 82,46 & \\
\hline \multirow{2}{*}{ Отношение: талия/бедра } & БГУФК & 0,83 & 0,04 & 0,81 & 0,83 & 0,85 & \multirow{2}{*}{0,001} \\
\hline & БГУ & 0,81 & 0,05 & 0,77 & 0,81 & 0,84 & \\
\hline
\end{tabular}


Таблица 5 (продолжение)

\begin{tabular}{|c|c|c|c|c|c|c|c|}
\hline \multirow{2}{*}{$\begin{array}{l}\text { Морфологические } \\
\text { показатели }\end{array}$} & \multirow{2}{*}{ Выборки } & \multirow{2}{*}{$\mathbf{M}$} & \multirow{2}{*}{ SD } & \multicolumn{3}{|c|}{ Процентили } & \multirow{2}{*}{$\mathbf{p}$} \\
\hline & & & & $25 \%$ & $50 \%$ & $75 \%$ & \\
\hline \multirow{2}{*}{ ИМТ } & БГУФК & 23,79 & 3,11 & 21,63 & 23,21 & 24,98 & \multirow{2}{*}{$0,05-0,9$} \\
\hline & БГУ & 22,78 & 3,60 & 20,47 & 22,34 & 24,30 & \\
\hline \multirow{2}{*}{ 2D:4D (правая рука) } & БГУФК & 0,96 & 0,04 & 0,93 & 0,96 & 0,98 & \multirow{2}{*}{0,001} \\
\hline & БГУ & 0,98 & 0,04 & 0,95 & 0,98 & 1,01 & \\
\hline \multirow{2}{*}{ 2D:4D (левая рука) } & БГУФК & 0,96 & 0,03 & 0,94 & 0,96 & 0,98 & \multirow{2}{*}{0,001} \\
\hline & БГУ & 0,98 & 0,04 & 0,95 & 0,98 & 1,00 & \\
\hline \multirow{2}{*}{ Динамометрия } & БГУФК & 44,02 & 7,10 & 39,50 & 44,00 & 48,00 & \multirow{2}{*}{0,001} \\
\hline & БГУ & 37,96 & 6,37 & 32,50 & 38,50 & 41,50 & \\
\hline
\end{tabular}

Девушки

\begin{tabular}{|c|c|c|c|c|c|c|c|}
\hline \multirow{2}{*}{ Индекс Таннера } & БГУФК & 81,81 & 5,11 & 77,90 & 81,40 & 85,20 & \multirow{2}{*}{0,05} \\
\hline & БГУ, БГПУ & 80,18 & 5,13 & 76,80 & 80,70 & 83,80 & \\
\hline \multirow{2}{*}{ Индекс Мартиросова } & БГУФК & 38,22 & 12,15 & 30,71 & 39,34 & 45,67 & \multirow{2}{*}{0,001} \\
\hline & БГУ, БГПУ & 26,93 & 10,53 & 18,89 & 26,76 & 34,45 & \\
\hline \multirow{2}{*}{ Отношение: талия/бедра } & БГУФК & 0,74 & 0,04 & 0,71 & 0,75 & 0,77 & \multirow{2}{*}{0,001} \\
\hline & БГУ, БГПУ & 0,72 & 0,04 & 0,69 & 0,72 & 0,75 & \\
\hline \multirow{2}{*}{ ИМТ } & БГУФК & 21,65 & 2,70 & 19,93 & 21,31 & 22,81 & \multirow{2}{*}{-} \\
\hline & БГУ, БГПУ & 21,25 & 3,45 & 19,00 & 20,58 & 22,83 & \\
\hline \multirow{2}{*}{ 2D:4D (правая рука) } & БГУФК & 0,97 & 0,03 & 0,95 & 0,98 & 1,00 & \multirow{2}{*}{0,01} \\
\hline & БГУ, БГПУ & 0,99 & 0,04 & 0,96 & 0,99 & 1,01 & \\
\hline \multirow{2}{*}{ 2D:4D (левая рука) } & БГУФК & 0,97 & 0,04 & 0,94 & 0,98 & 1,00 & \multirow{2}{*}{0,01} \\
\hline & БГУ, БГПУ & 0,99 & 0,04 & 0,97 & 0,99 & 1,02 & \\
\hline \multirow{2}{*}{ Динамометрия } & БГУФК & 27,74 & 4,63 & 25,25 & 28,25 & 30,00 & \multirow{2}{*}{0,001} \\
\hline & БГУ, БГПУ & 22,68 & 4,07 & 20,00 & 23,00 & 25,00 & \\
\hline
\end{tabular}

Особого внимания заслуживает анализ различий между рассматриваемыми группами юношей и девушек по пальцевому индексу. При его относительно стабильных значениях в онтогенезе, показатель рассматривается как возможный маркер уровня пренатального тестостерона и его связь с физическими возможностями остается предметом обсуждения во многих исследованиях. 
Сопоставление средних значений 2D:4D у студентов обоего пола с высоким и обычным уровнем физической подготовки позволило выявить достоверные различия между группами (у юношей $\mathrm{p}<0,001$, у девушек $\mathrm{p}<0,05$ ).

Полученные результаты согласуются с выводами других исследователей. Польские студенты мужского пола с меньшим значением 2D:4D, как правило, показывают лучшие результаты испытаний на выносливость (Koziel et al. 2017), а польские студентки, добровольно выбравшие занятия единоборствами, имеют более низкие значения пальцевого индекса, чем девушки, выбравшие аэробику, при том, что обе группы девушек имели схожую физическую подготовку и размеры тела (Kociuba et al. 2017). Низкий коэффициент 2D:4D правой руки является предиктором высоких результатов в регби (Bennett et al. 2010) и коррелирует с высокими способностями к серфингу у мужчин (Kilduff, Cook, Manning 2011). Зафиксирована также значительная отрицательная корреляция эргометрических показателей на дистанции 2000 м (гребля) с пальцевым индексом мужчин (Longman et al. 2011). Женщины с меньшими значениями 2D:4D в гребле имели лучшие результаты гонки, чем женщины с большими значениями 2D:4D (Hull et al. 2015). Выбор женщинами «мужественных» профессий также имел ассоциацию с пальцевым индексом: женщины-полицейские, по сравнению с женщинами контрольной группы, были выше и имели большую мышечную силу, но имели более низкий 2D:4D правой руки и средний 2D:4D для обеих рук (Kozieł et al. 2018).

\section{Выводы}

Анализ отдельных антропометрических показателей и рассчитанных на их основе индексов маскулинности/фемининности позволил установить следующие особенности их изменчивости у современной студенческой молодежи Беларуси.

1. У современных юношей обхват талии больше, чем у юношей начала XXI века. У девушек масса тела и обхват талии показали бо́льшую стабильность во времени.

2. Ширина таза у представителей обоих полов от начала века к современности уменьшилась.

3. У современных юношей дисгармоничность телосложения за счет избыточности массы тела встречается чаще, чем в начале века.

4. Показатели кистевой динамометрии у современной белорусской студенческой молодежи стали меньше по сравнению с началом столетия.

5. Юноши и девушки, с высоким уровнем физической подготовки, характеризуются более низкими значениями пальцевого индекса, чем те, кто имеет более низкий уровень двигательной активности.

Таким образом, выявлены особенности изменчивости во времени у студенческой молодежи Беларуси таких показателей как обхват талии, ширина таза и динамометрия (силовые возможности), которые отразились на динамике индексов маскулинности. Изменчивость показателей маскулинности также связана с уровнем двигательной активности юношей и девушек. 


\section{Научная литература}

Бахолдина В.Ю., Негашева М.А. Эволюция и морфология человека: учебное пособие. Москва: Издательство Московского университета, 2014. 344 с.

Дерябин B.E. Лекции по общей соматологии человека. Часть 1. Тотальные размеры тела и частные свойства телосложения. М.: Московский государственный университет, 2008. 242 с.

Ляликов С.А., Орехов С.Д. Физическое развитие детей Беларуси. Гродно: Издательство ГрГMУ, 2000. $220 \mathrm{c}$.

Мартиросов Э.Г., Руднев С.Г., Николаев Д.В. Применение антропологических методов в спорте, спортивной медицине и фитнесе. Москва: Физическая культура, 2009. 144 с.

Мартиросов Э.Г., Семенов М.М., Мартиросова К.Э. Определение фенотипического пола с учетом морфо-функциональных показателей // Актуальные вопросы антропологии, 2017. Вып. 12. С. 127-138.

Саливон И.И. Сравнительная характеристика телосложения белорусов и потомков от межнациональных браков // Актуальные вопросы антропологии, 2019. Вып. 14. С. 204-221.

Скриган Г.В. Динамометрия как показатель силовых возможностей и ее изменчивость у городских школьников Беларуси 12-15 лет // Актуальные вопросы антропологии, 2009. Вып.4. С. 104-111.

Хрисанфова Е.Н., Перевозчиков И.В. Антропология: учебник. Москва: Наука, 2005.400 с.

Чаплинская E.B. и др. Физическое развитие белорусских и сербских студентов: динамика во времени и межэтнические различия // Актуальные вопросы антропологии, 2019. Вып. 14. C. $364-377$.

Ямпольская Ю.А. Об изменении показателя динамометрии у школьников Москвы за последние десятилетия // Гигиена и санитария, 1993. № 9. С. 27-29.

Barrett E. et al. Digit ratio, a proposed marker of the prenatal hormone environment, is not associated with prenatal sex steroids, anogenital distance, or gender-typed play behavior in preschool age children // Journal of Developmental Origins of Health and Disease, 2020. No. 18 December. P. 1-10. doi: 10.1017/S2040174420001270.

Bennett M. et al. Digit ratio (2D:4D) and performance in elite rugby players // Journal of Sport Science, 2010. Vol. 28 (13). P. 1415-1421. doi: 10.1080/02640414.2010.510143.

Dinescu D. at el. Socioeconomic modifiers of genetic and environmental influences on body mass index in adult twins // Health Psychology, 2016. Vol. 35. P. 157-166. Doi: 10.1037/hea0000255.

Hull M.J. et al. Relationships between digit ratio (2D:4D) and female competitive rowing performance // American Journal of Human Biology, 2015. Vol. 27. P. 157-163. doi: 10.1002/ajhb.22627.

Hume D.K., Montgomerie R. Facial Attractiveness Signal Different Aspects of "Quality" in Women and Men // Evolution and Human Behavior, 2001. Vol. 22. Р. 93-112. Доступ: https://doi. org/10.1016/S1090- 5138(00)00065-9 (дата обращения: 14.07.2021).

Kilduff L.P., Cook C.J., Manning J.T. Digit ratio (2D:4D) and performance in male surfers // The Journal of Strength \& Conditioning Research, 2011. Vol. 25. P. 3175-3180. doi: 10.1519/ JSC.0b013e318212de8e.

Kociuba M. et al. Sports preference and digit ratio (2d:4d) among female students in Wrocław, Poland // Journal of Biosocial Science, 2017. Vol. 49(5). P. 623-633. doi: 10.1017/ S0021932016000523.

Koziet S. et al. Physical Fitness And Digit Ratio (2D:4D) In Male Students From Wrocław, Poland // Collegium Antropologicum, 2017. Vol.41(1). P. 31-37.

Koziet S. et al. Further evidence of an association between low second-to-fourth digit ratio (2D:4D) and selection for the uniformed services: a study among police personnel in Wrocław, Poland // Journal of Biosocial Science, 2018. Vol. 50 (4). P. 527-539. Doi: 10.1017/S0021932017000438.

Kurzban R., Weeden J. HurryDate: Mate Preferences in Action // Evolution and Human Behavior, 2005. Vol. 26 (3). Р. 227-244. Доступ: https://doi.org/10.1016/j.evolhumbehav.2004.08.012 (дата обращения: 23.07.2021). 
Longman D., Stock J.T., Wells J.C. Digit ratio (2D:4D) and rowing ergometer performance in males and females // American Journal of Physical Anthropology, 2011. Vol. 144. P. 337-341. doi: 10.1002/ajpa.21407.

Manning J.T. Digit ratio: A pointer to fertility, behavior and health. New Jersey: Rutgers University Press, 2002.

Manning J.T. et al. The ratio of 2 nd to 4th digit length: a predictor of sperm numbers and concentrations of testosterone, luteinizing hormone and oestrogen // Human Reproduction, 1998. Vol.13(11). P. 3000-3004. doi:10.1093 / humrep / 13.11.3000.

Mustelin L. et al. Physical activity reduces the influence of genetic effects on BMI and waist circumference: a study in young adult twins // International Journal of Obesity, 2009. Vol. 33. P. 29-36. Doi: 10.1038/ijo.2008.258.

Schrempft S. et al. Variation in the heritability of child body mass index by obesogenic home environment // JAMA Pediatrics, 2018. Vol. 172. P. 1153-1160. Doi: 10.1001/jamapediatrics.2018.1508.

Shabnam Suprava D., Devangan V., Stklanina L. Waist-to-hip ratio and body fat percentage: Indian teenagers vs. Africans (contemporary anthropometric review) // Український морфологічний альманах. 2014. Т. 17, № 2. С. 36-38. Доступ: http://umorphal.inf.ua/UMorphA_2014/ UMorphA_2014_2/ru/11.pdf (дата обращения: 12.07.2021).

Silventoinen $K$. et al. Genetic and environmental effects on body mass index from infancy to the onset of adulthood: an individual-based pooled analysis of 45 twin cohorts participating in the COllaborative project of Development of Anthropometrical measures in Twins (CODATwins) // The American Journal of Clinical Nutrition, 2016. Vol. 104. P. 371-379. doi: 10.3945/ajcn.116.130252.

Tovée M.J. et al. Human Female Attractiveness: Waveform Analysis of Body Shape // Proceedings of the Royal Society of London B: Biological Sciences, 2002. Vol. 269. Р. 2205-2213. Доступ: https://doi. org/10.1098/rspb.2002.2133 (дата обращения: 15.07.2021).

Van Anders S.M., Hampson E. Waist-to-hip ratio is positively associated with bioavailable testosterone but negatively associated with sexual desire in healthy premenopausal women // Psychosomatic Medicine, 2005. Vol. 67, no. 2. P. 246-250. Doi: 10.1097/01.psy.0000151747.22904.d7.

WHO: Waist circumference and waist-hip ratio: report of a WHO expert consultation, Geneva, 8-11 December 2008. Доступ: http://whqlibdoc.who.int/publications/2011/9789241501491_ eng.pdf (дата обращения: 17.07.2021).

Yong Shao et al. Waist-hip ratio correlates with the levels of reproductive endocrine hormones in abdominally obese males // Zhonghua Nan Ke Xue. 2013. Vol. 19, no. 7. P. 634-636 (PMID: 23926682).

Kasparova, Elena N., Skryhan, Halina U., and Dunai Valery I.

DOI: $10.33876 / 2311-0546 / 2021-3 / 134-151$

\section{Variability of masculine indicators among young students in Belarus}

The study aims to assess the variability of morphofunctional indicators of masculinity among students in Belarus over time and depending on the level of physical fitness. The research was carried out in 2016-2021 in Minsk (the Republic of Belarus). The sample consisted of 233 students (102 young men, 131 young women) aged 18 to 22. We also used the materials of our earlier study of 180 students (125 young men and 65 young women) of the Belarusian State University of Physical Culture. We compared our data to the archival data of the Department of Anthropology of the National Academy of Sciences of Belarus from the period 2000-2007: a total of 243 students in Minsk (98 young men, 145 young women). Anthropometric measurements of body length, body weight, shoulder width, pelvic width, waist circumference, hip circumference, tense shoulder circumference, relaxed shoulder 
circumference, length of the second and fourth fingers of both hands, wrist dynamometry of the right and left hand were carried out. The morphological indices were calculated. It was revealed that modern young men have more waist circumference than young men of the beginning of the XXI century. In young women, waist circumference and body weight showed greater stability. The width of the pelvis has decreased from the beginning of the 21 st century to the present in both sexes. In modern young men, disharmony of physique due to excess body weight in relation to its length occurs more often than at the beginning of the century. The indicators of wrist dynamometry among modern Belarusian students have become lower compared to the beginning of the 2000s. The young men and women involved in physical culture had a significantly lower 2D:4D for the left hand and right hand than those who have a lower level of physical fitness. Thus, the study revealed the temporal variability of waist circumference, pelvic width, and dynamometry (strength capabilities) and the dynamics of morphological indices of masculinity among young students in Belarus.

Keywords: anthropometric indicators, indices of masculinity/femininity, student youth of Belarus

For Citation: Kasparova, E.N., H.U. Skryhan, and V.I. Dunai. 2021. Variability of Masculine Indicators Among Young Students in Belarus. Herald of Anthropology (Vestnik Antropologii) 3: 134-151.

Author Info: Kasparova, Elena N. - senior lecture, Department of Pedagogy and Problems of Education Development, Belarusian State University (Republic of Belarus, Minsk, 220030, 4 Nezavisimosti Avenue).E-mail: elena_arts@mail.ru

Skryhan, Halina U. - PhD in Biological sciences, Associate Professor, Department of Correction and Development Technologies, Belarusian State Pedagogical University named after Maxim Tank (Republic of Belarus, Minsk, 220030, Sovetskaya, 18). E-mail: galanca@mail.ru

Dunai, Valery I. - PhD in Biological sciences, Associate Professor, Rector, Educational institution «Polessky State University» (Republic of Belarus, Pinsk, 225710, Dneprovskoy Flotilii, 23).E-mail: dunay_wal@bk.ru

Funding: The study was conducted with the financial support of the following organizations and grants: BRFFI, Contract G21MS-022 of 01.07.2021 "Social and biological factors of adaptation of student youth of Belarus and Serbia to the changing conditions of the modern environment"

\section{References}

Bakholdina, V.Yu., and M.A. Negasheva. 2014 Evoliutsiia i morfologiia cheloveka: uchebnoe posobie [Evolution and human morphology]. Moscow: Izdatel'stvo Moskovskogo universiteta.

Deriabin, V.E. 2008 Lektsii po obshchei somatologii cheloveka. Total'nye razmery tela i chastnye svoistva teloslozheniia [Lectures on general human dentistry. Part 1. Total body size and specific properties of the physique]. Moscow: Moskovskii gosudarstvennyi universitet.

Lialikov, S.A., and S.D. Orekhov. 2000 Fizicheskoe razvitie detei Belarusi [Physical development of children in Belarus]. Grodno: Izdatel'stvo GSMU.

Martirosov, E.G., S.G. Rudnev, and D.V. Nikolaev. 2009. Primenenie antropologicheskikh metodov $v$ sporte, sportivnoi meditsine i fitnese [Using of anthropological methods in sports, sports medicine and fitness]. Moscow: Fizicheskaia kul'tura. 
Martirosov, E.G., M.M. Semenov, and K.E. Martirosova 2017. Opredelenie fenotipicheskogo pola $s$ uchetom morfo-funktsional'nykh pokazatelei [Determination of the phenotypic sex taking into account morphofunctional indicators]. Aktual'nye voprosy antropologii 12: 127-138.

Salivon, I.I. 2019. Sravnitel'naia kharakteristika teloslozheniia belorusov i potomkov ot mezhnatsional'nykh brakov [Comparative analysis of the body types of belarusians and descendants from inter-ethnic marriage]. Aktual'nye voprosy antropologii 14: 204-221.

Skrigan, G.V. 2009. Dinamometriia kak pokazatel' silovykh vozmozhnostei i ee izmenchivost'u gorodskikh shkol'nikov Belarusi 12-15 let [Dynamometry as a parameter of power opportunities]. Aktual'nye voprosy antropologii 4: 104-111.

Hrisanfova, E.N., I.V. Perevozchikov. 2005. Antropologiia: uchebnik [Antropology]. Moscow: Nauka.

Chaplinskaia, E.V. et al. 2019. Fizicheskoe razvitie belorusskikh i serbskikh studentov: dinamika vo vremeni i mezhetnicheskie razlichiia [Physical development of belarusian and serb students: dynamics in tim and interethnical differences]. Aktual'nye voprosy antropologii 14: 364-377.

Yampol'skaia, Yu.A. 1993. Ob izmenenii pokazatelia dinamometrii u shkol'nikov Moskvy za poslednie desiatiletiia [About the change in the dynamometry index in Moscow schoolchildren over the past decades]. Gigiena i sanitaria 9: 27-29.

Barrett, E. et al. 2020. Digit ratio, a proposed marker of the prenatal hormone environment, is not associated with prenatal sex steroids, anogenital distance, or gender-typed play behavior in preschool age children. Journal of Developmental Origins of Health and Disease, 18 December: 1-10. Doi: 10.1017/S2040174420001270.

Bennett, M. et al. 2010 Digit ratio (2D:4D) and performance in elite rugby players. Journal of Sport Science 28(13): 1415-1421. doi: 10.1080/02640414.2010.510143.

Dinescu, D. et al. 2016. Socioeconomic modifiers of genetic and environmental influences on body mass index in adult twins. Health Psychology 35: 157-166. doi: 10.1037/hea0000255.

Hull, M.J. et al. 2015. Relationships between digit ratio (2D:4D) and female competitive rowing performance. American Journal of Human Biology 27: 157-163. doi: 10.1002/ajhb.22627.

Hume, D.K., and R. Montgomerie, 2001. Facial Attractiveness Signal Different Aspects of "Quality" in Women and Men. Evolution and Human Behavior 22: 93-112. https://doi.org/10.1016/ S1090- 5138(00)00065-9.

Kilduff, L.P., C.J. Cook, and J.T. Manning, 2011. Digit ratio (2D:4D) and performance in male surfers. The Journal of Strength \& Conditioning Research 25: 3175-3180. Doi: 10.1519/ JSC.0b013e318212de8e.

Kociuba, M. et al. 2017. Sports preference and digit ratio (2d:4d) among female students in Wrocław, Poland. Journal of Biosocial Science 49 (5): 623-633. Doi: 10.1017/S0021932016000523.

Kozieł, S. et al. 2017. Physical Fitness And Digit Ratio (2D:4D) In Male Students From Wrocław, Poland. Collegium Antropologicum 41 (1): 31-37.

Koziel, S. et al. 2018. Further evidence of an association between low second-to-fourth digit ratio (2D:4D) and selection for the uniformed services: a study among police personnel in Wrocław, Poland. Journal of Biosocial Science 50 (4): 527-539. Doi: 10.1017/S0021932017000438.

Kurzban, R., and J. Weeden, 2005. HurryDate: Mate Preferences in Action. Evolution and Human Behavior 26 (3): 227-244. Https://doi.org/10.1016/j.evolhumbehav.2004.08.012.

Longman, D., J.T. Stock, and J.C. Wells. 2011. Digit ratio (2D:4D) and rowing ergometer performance in males and females. American Journal of Physical Anthropology 144: 337-341. Doi: 10.1002/ajpa.21407.

Manning, J. T. 2002. Digit ratio: A pointer to fertility, behavior and health. New Jersey: Rutgers University Press.

Manning, J.T. et al. 1998. The ratio of 2nd to 4th digit length: a predictor of sperm numbers and concentrations of testosterone, luteinizing hormone and oestrogen. Human Reproduction 13 (11): 3000-3004. Doi:10.1093/humrep/13.11.3000. 
Mustelin, L. et al. 2009. Physical activity reduces the influence of genetic effects on BMI and waist circumference: a study in young adult twins. International Journal of Obesity 33: 29-36. Doi: 10.1038/ijo.2008.258.

Schrempft, S. et al. 2018. Variation in the heritability of child body mass index by obesogenic home environment. JAMA Pediatrics 172: 1153-1160. Doi: 10.1001/jamapediatrics.2018.1508.

Shabnam Suprava, D., V. Devangan, and L. Stklanina, 2014. Waist-to-hip ratio and body fat percentage: Indian teenagers vs. Africans (contemporary anthropometric review). Ukrai'ns 'kyj morfologichnyj al'manah 17 (2): 36-38. Http:/umorpha1.inf.ua/UMorphA_2014/UMorphA_2014_2/ru/11.pdf.

Silventoinen, K. et al. 2016. Genetic and environmental effects on body mass index from infancy to the onset of adulthood: an individual-based pooled analysis of 45 twin cohorts participating in the COllaborative project of Development of Anthropometrical measures in Twins (CODATwins). The American Journal of Clinical Nutrition 104: 371-379. Doi: 10.3945/ajcn.116.130252.

Tovée, M.J. et al. 2002. Human Female Attractiveness: Waveform Analysis of Body Shape. Proceedings of the Royal Society of London B: Biological Sciences 269: 2205-2213. Https://doi. org/10.1098/rspb.2002.2133.

Van Anders, S.M., and E. Hampson, 2005. Waist-to-hip ratio is positively associated with bioavailable testosterone but negatively associated with sexual desire in healthy premenopausal women. Psychosomatic Medicine 67 (2): 246-250. Doi: 10.1097/01.psy.0000151747.22904.d7.

WHO: Waist circumference and waist-hip ratio: report of a WHO expert consultation, Geneva, 8-11 December 2008. Http://whqlibdoc.who.int/publications/2011/9789241501491_eng.pdf.

Yong Shao, et al. 2013. Waist-hip ratio correlates with the levels of reproductive endocrine hormones in abdominally obese males. Zhonghua Nan Ke Xue 19 (7): 634-636. PMID: 23926682. 